\title{
Development of controlled micro-discharge at the atmospheric pressure
}

\author{
Mingon Park • Yoshinori Hirata • Tatsumasa Urabe
}

Received: 18 December 2012 / Accepted: 9 August 2013 / Published online: 7 September 2013

(C) The Author(s) 2013. This article is published with open access at Springerlink.com

\begin{abstract}
The generation method of sub-millimeter sized plasma was developed through controlling the electrical discharge in the range from glow to arc discharge with use of the experimental torch device and the newly designed high-voltage power source. The electrical discharge was established between a cathode of the electrolytic polished tungsten electrode and an anode of stainless steel sheet. Features of the thermal materials processing by micro-discharge were experimentally investigated. It is shown that the power density of micro-discharge reaches higher than $10^{9} \mathrm{~W} / \mathrm{m}^{2}$ and sub-millimeter sized melt spot can be obtained at the surface of anode metal.
\end{abstract}

Keywords Capacitor discharge welding · Precision .

ATIG welding $\cdot$ Cathodes $\cdot$ Electrolysis

\section{Introduction}

Fusion welding processes have been practically applied to not only welding of large-scale steel structures but also precision welding for various small parts in automobile and turbine blades in power plants. Precision welding process is normally carried out with the use of laser or electron beam because it is possible to reduce the heat input and the beam diameter less than $0.1 \mathrm{~mm}$ [1]. But there are several problems such as the expensive machine, high running cost, low-energy efficiency, and so on.

Recently, precision welding with small-sized discharge process at atmospheric pressure is strongly demanded in order to realize low-cost manufacturing. Plasma arc welding process

Doc. IIW-2408, recommended for publication by Study Group SG-212 "The Physics of Welding"

M. Park $\cdot$ Y. Hirata $(\triangle) \cdot$ T. Urabe

Division of Materials and Manufacturing Science, Graduate School

of Engineering, Osaka University, 2-1, Yamada-oka, Suita,

Osaka 565-0871, Japan

e-mail: hirata@mapse.eng.osaka-u.ac.jp is practically used for precise welding of bellows, steel sheets, automobile parts, and so on. For example, we can obtain weld bead of 1-mm width for stainless steel sheet of around 0.2-mm thickness by using plasma arc welding with low current but better precise processing may not be expected $[2,3]$. One of the authors conducted in situ experiment of the vacuum discharge in sub-micrometer gap between needle-like cathode and plane anode in scanning electron microscope. In the experiment, they used two types of the pointed tungsten electrode by electrolytic polishing and carbon nanotube formed at the end of the electrode. The electric field at the electrode surface is strengthened by extreme decrease of curvature radius of the electrode tip. Then, electrons are fieldemitted from the pointed cathode tip and flow into the anode. Those electrons heat the anode surface due to condensation from free space. The vacuum discharge process could form a melt spot of several micrometers at the anode surface [4-6]. However, it seems not to be the proper process for practical application to the relevant manufacturing fields described above.

In this work, we aimed to investigate how to establish electrical gaseous discharge of very small sizes at the atmospheric pressure. Then, we focused on the electrode shape and constriction of plasma current path. The electrical discharge was experimentally investigated in the range from glow to arc region through glow-arc transition region by using both of the tungsten inert gas (TIG) type torch and the plasma-type torch. And in order to investigate various types of electric discharge, we designed and developed the experimental power supply.

\section{Experimental apparatus and procedure}

\subsection{Experimental apparatus}

Figure 1 shows the schematic illustration of experimental torches used. As shown, the nozzle diameter of the TIG-type 


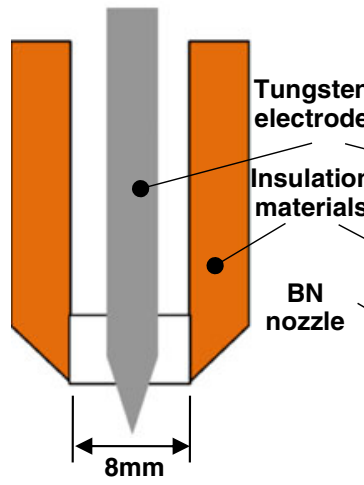

(a) TIG type torch

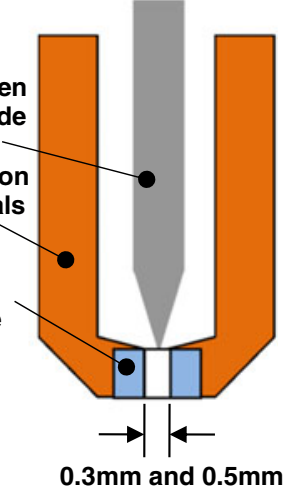

(b) Plasma type torch

Fig. 1 Schematic illustration of experimental torches used

torch is $8 \mathrm{~mm}$ and the tungsten electrode is extended from the nozzle end. In the plasma-type torch, the nozzle is made from boron nitride $(\mathrm{BN})$ ceramic which is usable up to around $3,000 \mathrm{~K}$. In order to constrict discharge current path, the nozzle diameter was reduced to $0.3 \mathrm{~mm}$.

The shape of the electrode tip influences the electrical breakdown, the discharge plasma shape, the current distribution in the plasma, and so on. The tungsten wire of $1 \mathrm{~mm}$ in diameter was used. The electrode tip was sharpened by two methods of mechanical polishing and electrolytic polishing in the sodium hydroxide solution $(\mathrm{NaOH} 2.5 \mathrm{~mol} / \mathrm{l})$ [7, 8]. Figure 2 shows the schematic illustration of electrolytic polishing device. Voltage and current in the electrolytic polishing process was carefully adjusted. The mechanical polished electrode was also used. The electrode shapes by both polishing methods are shown in Fig. 3. As shown, the electrolytic polished electrode is remarkably thin and the curvature radius of its tip is very pointed compared with those of mechanical polished electrode.

Figure 4 shows schematic illustration of the experimental power supply used. It consists of two high voltage power sources, two fast switches available for high voltage, and

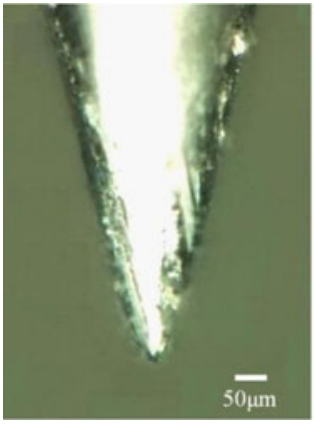

(a) Mechanical polished

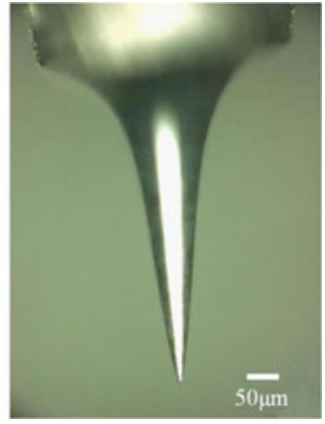

(b) Electrolytic polished

Fig. 3 Photographs of the electrode tip

Insulated Gate Bipolar Transistor (IGBT) which controls the current and voltage of the discharge load. Power supply-1 can supply $7 \mathrm{kV}-10 \mathrm{~mA}$ which is applied for the electrical breakdown of electrodes spacing. Power supply-2 supplies discharge power of voltage up to $1,000 \mathrm{~V}$ and current up to $1.2 \mathrm{~A}$. These two power supplies are switched according to the time chart shown in Fig. 5. Firstly, a trigger signal of $-7 \mathrm{~V}$ is input to power supply-1 from the pulse generator. Then, a high voltage of $-7 \mathrm{kV}$ is applied to the electrodes gap and electrical breakdown occurs. Next, switch-2 turns on just after switch-1 turns off by control of the pulse generator. Then, power supply-2 provides the constant current through IGBT at the voltage of $1,000 \mathrm{~V}$.

\subsection{Experimental procedure}

The schematic illustration of the experimental setup is shown in Fig. 6. The experimental condition of electric discharge is shown in Table 1. The tungsten electrode of 1-mm diameter was used and set in the torch. The electrode tip was shaped by both mechanical and electrolytic polishing methods. The vertex angle of $30^{\circ}$ was obtained by mechanical polish. The electrolytic polishing was carried out after completing the mechanical shaping of the tungsten electrode with a vertex

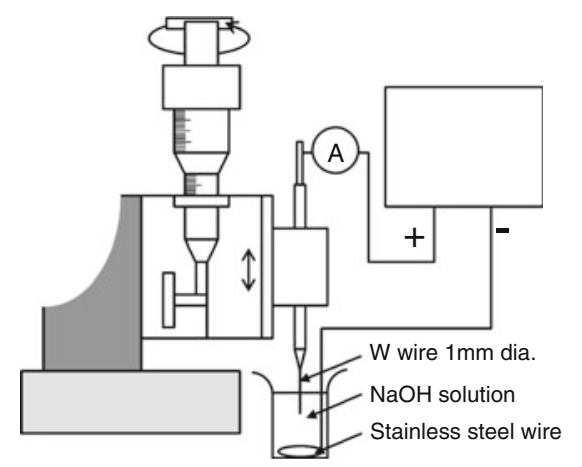

Fig. 2 Schematic illustration of electrolytic polishing device

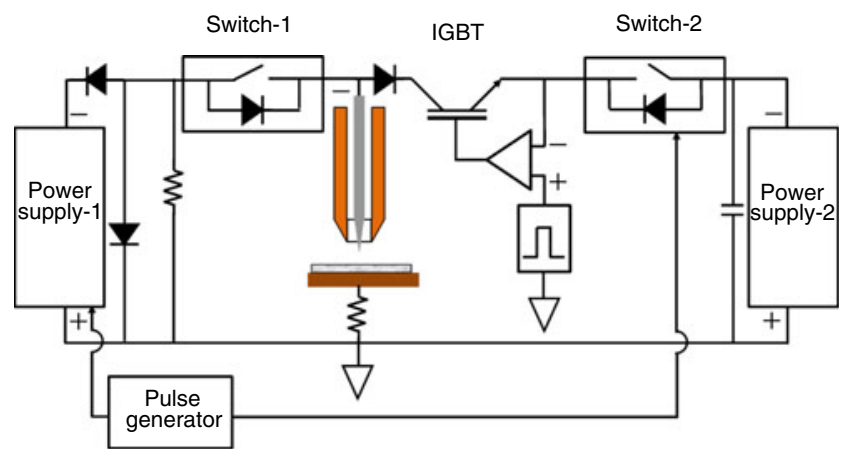

Fig. 4 Schematic illustration of the experimental power supply used 


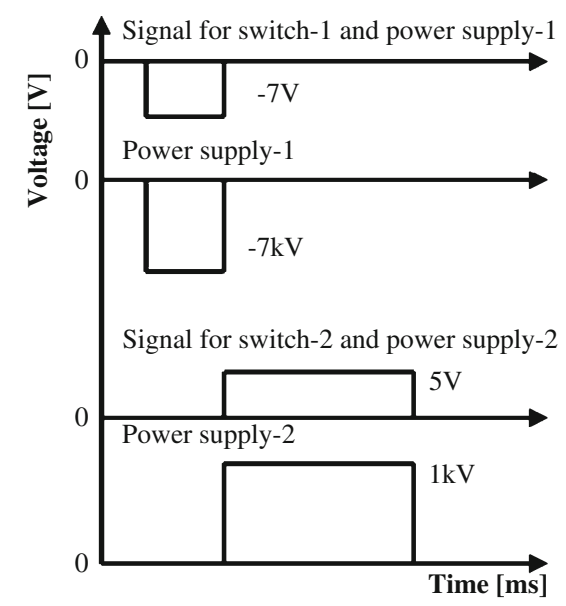

Fig. 5 Time chart of operating signal for the newly developed power supply

angle of $30^{\circ}$. Stainless steel sheet (SUS304 $0.07 \mathrm{~mm}$ thickness) was used for anode-base metal. The nozzle diameter was 0.3 and $0.5 \mathrm{~mm}$ for plasma-type torch and $8 \mathrm{~mm}$ for TIG-type torch, respectively. The Ar gas and $\mathrm{N}_{2}$ gas were used as plasma gas in this experiment $(0.2 \sim 2 \mathrm{~L} / \mathrm{min})$. The currentvoltage waveform was measured by oscilloscope. The appearance of electric discharge was observed using optical microscope set with high-speed CCD camera. The melting spot on the base metal surface was also observed by using optical microscope.

\section{Experimental results and discussion}

\subsection{TIG-type torch}

\subsubsection{Influence of the electrode tip shape on DC electric discharge}

It is well known that electron emission from cathode increases with increase of field strength at the electrode surface [4-6,

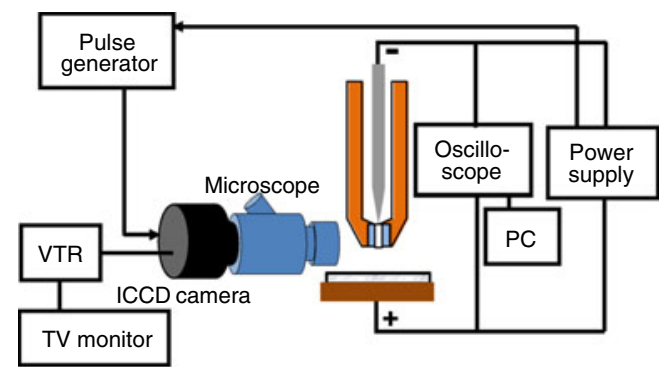

Fig. 6 Schematic illustration of the experimental setup
Table 1 Experimental condition of electrical discharge

\begin{tabular}{ll}
\hline Nozzle diameter [mm] & $0.3,0.5,0.7,8$ \\
Arc length [mm] & $1.5-4.5$ \\
Current [mA] & $20-1000$ \\
Shielding gas flow rate [L/min] & $0.2-2$ \\
Electrode diameter [mm] & 1.0 \\
Electrode vertex angle [degree] & 30 \\
Discharge time [ms] & 10 \\
Shielding gas & $\mathrm{Ar}, \mathrm{N}_{2}$ \\
\hline
\end{tabular}

9-11]. Figure 7 shows the electrode shape which is simplified to calculate the field strength. As for the configuration, the field strength can be obtained by the following equation [12]:

$E \approx \frac{V}{a[1-(a / d)]}$

where $E$ is the field strength [in volts per meter], $a$ is the radius of curvature [in meters], $d$ is the distance from base metal to tip of the electrode [in meters], and $V$ is the applied voltage [in volts]. It is recognized that the field strength



Fig. 7 Point and plane geometry with a hemispherical sharp point with radius $a$ located a distance above $b$, an infinite grounded plane 


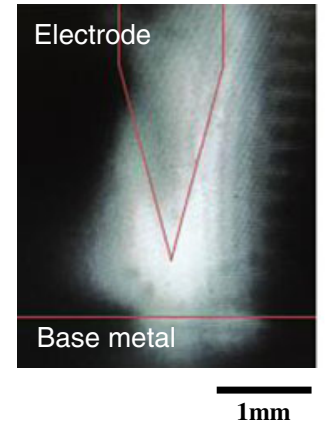

(a) Mechanical polished electrode

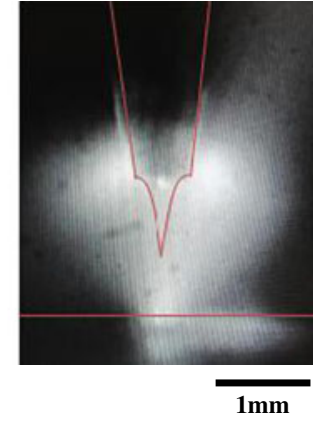

(b) Electrolytic polished electrode
Fig. 8 Appearance of Ar gas discharge with TIG-type torch

increases with the decrease of the radius of curvature at the electrode tip. In Fig. 3, the radius of curvature of the electrolytic polished electrode tip is $2.5 \mu \mathrm{m}$ and mechanical polished $21.7 \mu \mathrm{m}$. In the experiment, there is some scattering for radius curvature of the electrode tip. But it is definitely expected that the field strength at the electrolytic polished electrode tip is remarkably higher than that of the mechanical polished electrode tip. Then, the direct current (DC) discharge with electrolytic polished electrode is expected to be more stabilized than that with mechanical-polished electrode.

Figure 8 shows plasma appearances discharged with Argas for both mechanical-polished electrode and electrolytic polished electrode at the constant current of $500 \mathrm{~mA}$ in TIGtype torch. As seen in Fig. 8a, in the case of mechanical electrode, illumination is observed at the wide area of the electrode surface. The use of the electrolytic polished electrode seems to stabilize discharge plasma on the electrode tip as shown in Fig. 8b. Figure 9 shows voltage waveforms of DC discharge described above. As seen in Fig. 9a, the discharge voltage changes in the range of 50 and $200 \mathrm{~V}$. From both observations of high-speed pictures and voltage waveform, it is considered that the discharge mode changes between abnormal glow and non-thermal arc. Its discharge mode is called the glow-arc transition mode. In Fig. 9b, the average voltage is about $15 \mathrm{~V}$ and its change is very small compared with Fig. 9a. Thus, it is judged that arc discharge occurs.

Figure 10 shows the relationship between the current and voltage of DC discharge with Ar gas in TIG-type torch. In the

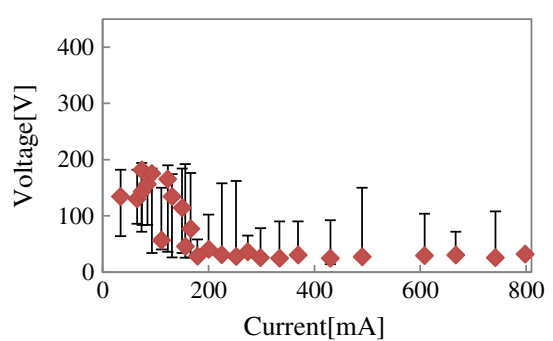

(a) Mechanical polished electrode

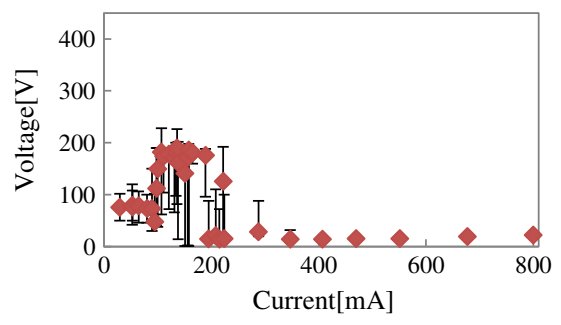

(b) Electrolytic polished electrode

Fig. 10 Relationship between current and voltage of Ar gas discharge with TIG-type torch

figure, average and fluctuation of the voltage are indicated by red colored circles and error bars, respectively. We classified discharge mode of the experimental results according to the universal electric characteristics of DC discharge [13]. In the case of mechanical polished electrode, it is supposed to have a glow discharge mode up to $70 \mathrm{~mA}$. Glow-arc transition discharge occurs from 70 to $730 \mathrm{~mA}$. In current higher than $730 \mathrm{~mA}$, arc discharge can be established. Whereas, electrolytic polished electrode lowers transition current of each discharge mode. That is up to $90 \mathrm{~mA}$ for glow region, from 90 to $350 \mathrm{~mA}$ for glow-arc transition region, and higher than $350 \mathrm{~mA}$ for arc region.

\subsubsection{Influence of shielding gas on DC discharge}

In the case of TIG arc welding, Ar gas is generally used as shielding gas. It is known that $\mathrm{N}_{2}$ gas reduces the plasma size of TIG arc and increases its power density [14]. As seen in Fig. 11 [15], both specific heat and thermal conductivity of $\mathrm{N}_{2}$ gas are higher than those of Ar gas at the elevated temperature. High values of specific heat and thermal conductivity suppresses the
Fig. 9 Voltage waveforms of Ar gas discharge with TIG-type torch



(a) Mechanical polished electrode

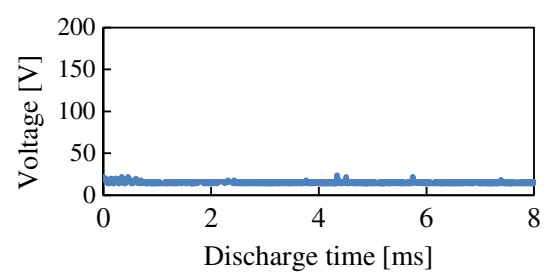

(b) Electrolytic polished electrode 


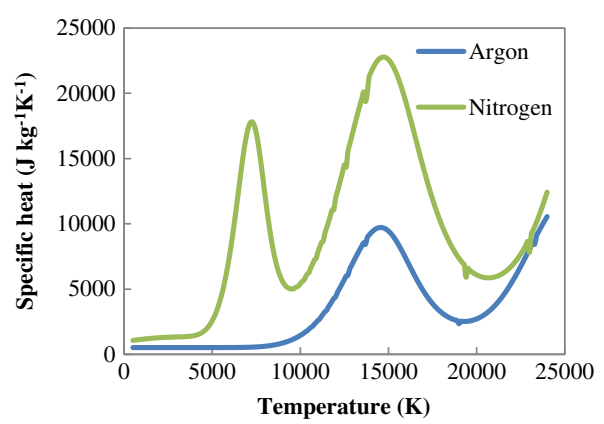

(a) Specific heat

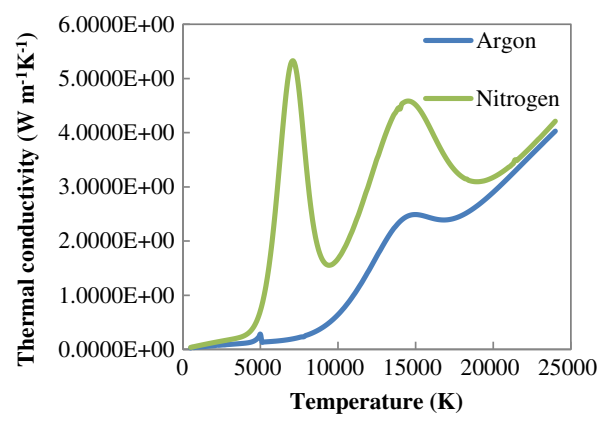

(b) Thermal conductivity

Fig. 11 Physical properties of $\mathrm{Ar}$ gas and $\mathrm{N}_{2}$ gas as a function of temperature

expansion of plasma volume. Reduction of plasma volume leads to constrict the current path and decrease the discharge diameter. Furthermore, it is known that the discharge voltage in $\mathrm{N}_{2}$ gas is higher than that in Ar gas at the same conditions [16, 17]. Then, in this work, we examined whether $\mathrm{N}_{2}$ gas shows the plasma constriction and higher discharge voltage.

Figure 12 shows $\mathrm{N}_{2}$ discharge appearance with TIG-type torch at the current of $500 \mathrm{~mA}$. Figure 12a and $\mathrm{b}$ are discharge appearances using mechanical polished electrode and electrolytic polished electrode, respectively. In the case of mechanical polished electrode, several cathode spots appear randomly at the electrode surface and discharge plasma is dispersed as

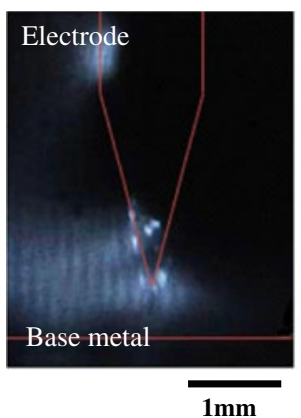

(a) Mechanical polished electrode

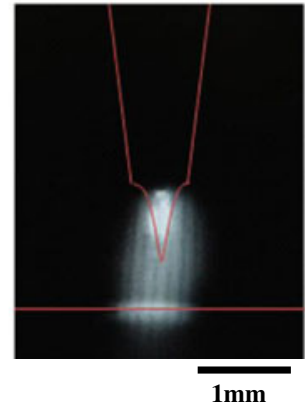

(b) Electrolytic polished electrode
Fig. 12 Appearance of $\mathrm{N}_{2}$ gas discharge with TIG-type torch

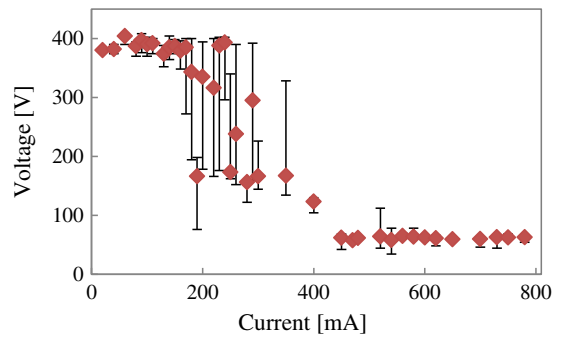

Fig. 13 Relationship between current and voltage of $\mathrm{N}_{2}$ gas discharge with TIG-type torch using electrolytic polished electrode

seen in Fig. 12a. By using electrolytic polished electrode, $\mathrm{N}_{2}$ gas discharge is stabilized as shown in Fig. 12b.

Figure 13 shows the relationship between the current and voltage of $\mathrm{N}_{2}$ gas discharge with TIG-type torch using electrolytic polished electrode. As seen in the case of $\mathrm{N}_{2}$ gas, glow-arc transition discharge occurs up to $430 \mathrm{~mA}$. Beyond $430 \mathrm{~mA}$, arc mode becomes dominant. Compared with Fig. 10b, the voltage of $\mathrm{N}_{2}$ gas discharge is higher than that of Ar gas discharge in the whole range of the current. In order to produce $\mathrm{N}_{2}$ gas plasma, dissociation and ionization energies must be injected. The experimental power supply is not possible to control to constantly keep the current lower than $20 \mathrm{~mA}$. Thus, we could not observe the normal glow discharge of $\mathrm{N}_{2}$ gas.

In Ar gas discharge process, no melting spot was formed. But $\mathrm{N}_{2}$ gas discharge provides higher power density at the anode surface which is caused by the reduction of plasma volume and high discharge voltage compared with Ar gas discharge. Then, melt spots could be formed by $\mathrm{N}_{2}$ gas discharge process as shown in Figs. 14 and 15. In the case of $\mathrm{N}_{2}$ discharge using mechanical polished electrode, the shape of the melt spot is not uniform and is distorted from the circle, and its size is not always depending on the current as shown in Fig. 14. In the case of the discharge using electrolytic polished electrode, the melting spot is in circular shape and it becomes

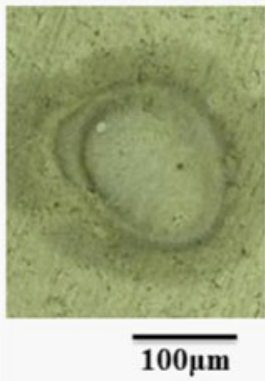

(a) $20 \mathrm{~mA}$

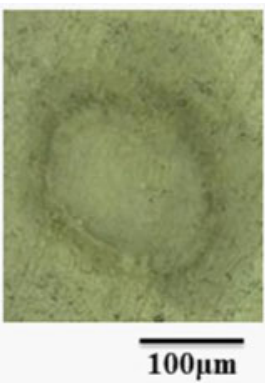

(b) $200 \mathrm{~mA}$

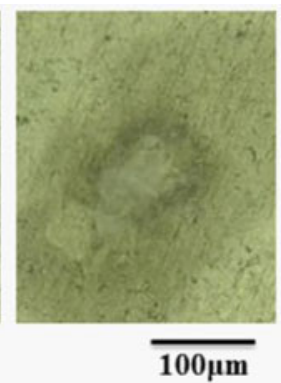

(c) $800 \mathrm{~mA}$
Fig. 14 Photographs of melting spots by $\mathrm{N}_{2}$ gas discharge with TIG-type torch using mechanical polished electrode 

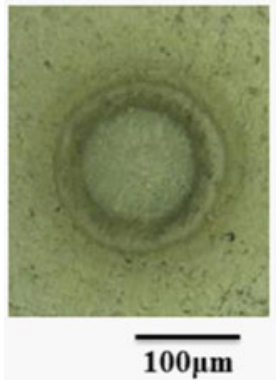


(b) $200 \mathrm{~mA}$



(c) $800 \mathrm{~mA}$ (a) $20 \mathrm{~mA}$

Fig. 15 Photographs of melting spots by $\mathrm{N}_{2}$ gas discharge with TIG-type torch using electrolytic polished electrode



$0.5 \mathrm{~mm}$

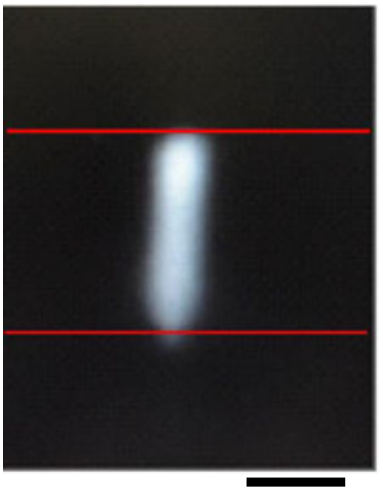

$0.5 \mathrm{~mm}$

(a) Mechanical polished

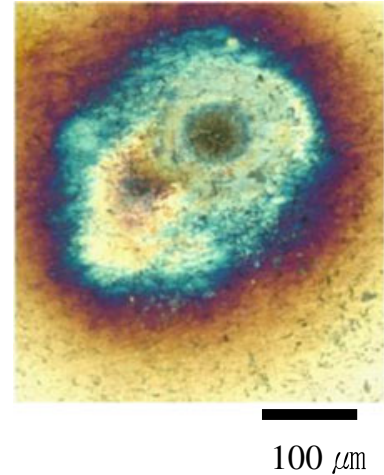

(a) Nozzle dia. $0.5 \mathrm{~mm}$

Mechanical polished

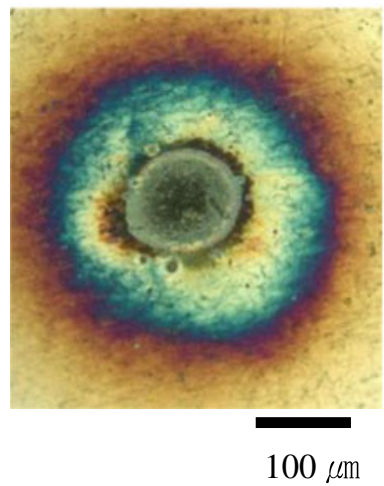

(c) Nozzle dia. $0.5 \mathrm{~mm}$

Electrolytic polished

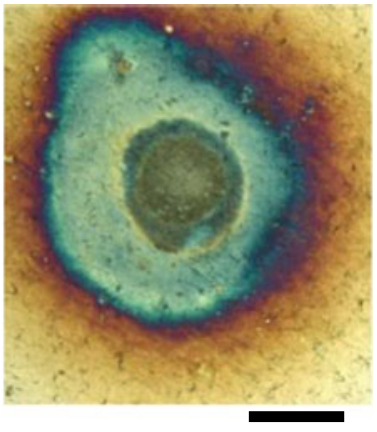

$100 \mu \mathrm{m}$

(b) Nozzle dia. $0.3 \mathrm{~mm}$

Mechanical polished

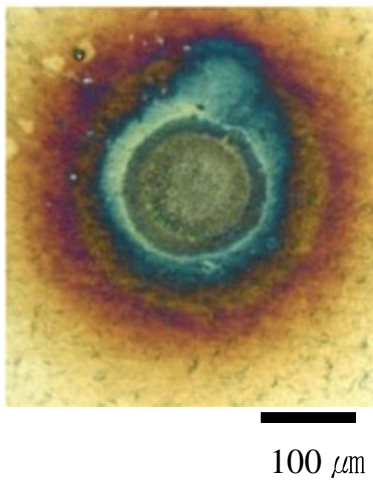

(d) Nozzle dia. $0.3 \mathrm{~mm}$

Electrolytic polished

Fig. 16 Appearance of Ar gas discharge with plasma type torch. (nozzle diameter $0.3 \mathrm{~mm}$; current 1,000 mA; gap length $3 \mathrm{~mm}$; discharge time 10 $\mathrm{ms}$; gas flow rate $0.2 \mathrm{~L} / \mathrm{min}$ )

larger with the increase of the current. These experimental results show the possibility of precision melting process of sub-millimeter size by $\mathrm{N}_{2}$ gas discharge with TIG-type torch using electrolytic polished electrode.

\subsection{Plasma-type torch}

Figure 16 shows the appearances of Ar gas discharge with plasma-type torch at 1,000 mA. The diameter of BN nozzle in the photographs is $0.3 \mathrm{~mm}$. As seen, beam-like discharge that

Fig. 18 Photographs of melting spots by Ar gas discharge with plasmatype torch

we call "plasma beam," is formed by using plasma-type torch. But the appearance of the plasma beam is somewhat different depending on the electrode used. The plasma beam, by using electrolytic polished electrode, is thinner and more stable than that by mechanical polished electrode.

Figure 17 shows the voltage waveforms of the plasma beams. The voltage, by using electrolytic polished electrode, is very stable as shown in Fig. 17b. From the experimental results of the TIG-type torch, it is considered that the cathode spot of electron emission is concentrated at the tip of the pointed electrode and wondering of discharge plasma does not occur.
Fig. 17 Voltage waveforms of Ar gas discharge with plasma-type torch

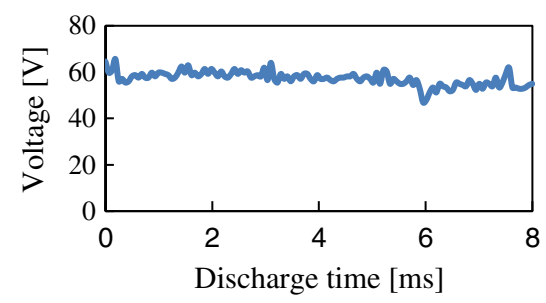

(a) Mechanical polished electrode

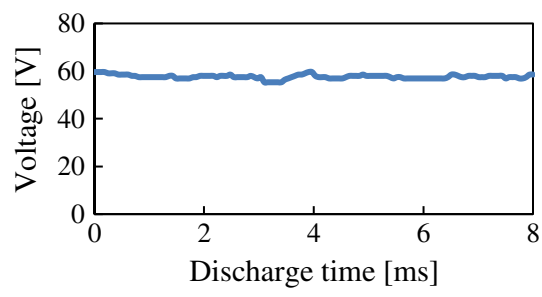

(b) Electrolytic polished electrode 


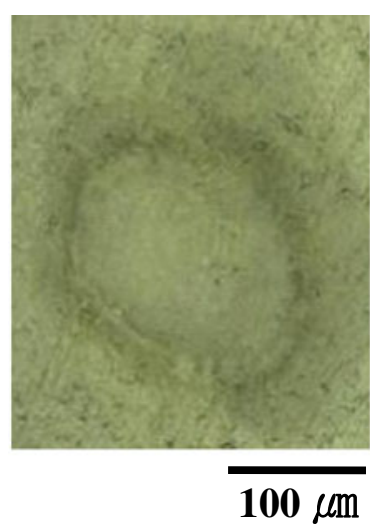

(a) Nozzle dia. $0.5 \mathrm{~mm}$ Mechanical polished

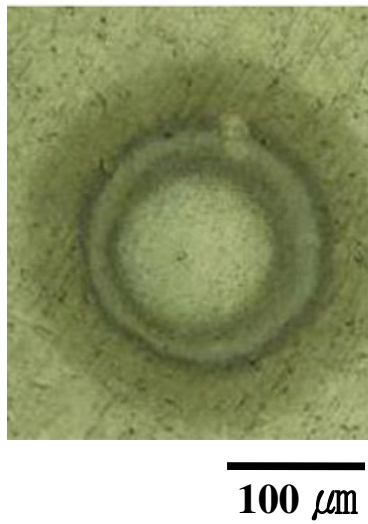

(c) Nozzle dia. $0.5 \mathrm{~mm}$ Electrolytic polished

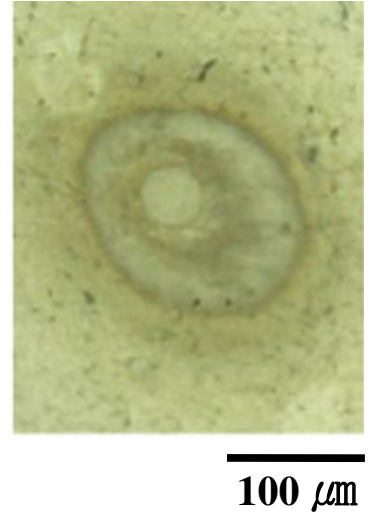

(b) Nozzle dia. $0.3 \mathrm{~mm}$ Mechanical polished

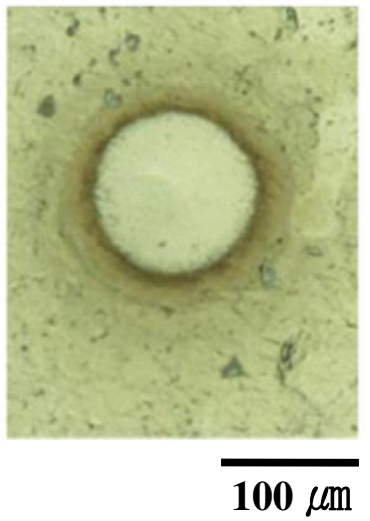

(d) Nozzle dia. $0.3 \mathrm{~mm}$ Electrolytic polished

Fig. 19 Photographs of melting spots by $\mathrm{N}_{2}$ gas discharge with plasmatype torch

Figure 18 shows melting spots by Ar gas plasma beam. The melting spot could not be formed in TIG-type torch for both mechanical polished electrode and electrolytic polished electrode. By using plasma-type torch, we could obtain the melting spot. This experimental result shows that the use of BN nozzle increases the power density of Ar gas discharge at the anode surface. Therefore, the current path of the discharge is constricted through the $\mathrm{BN}$ nozzle hole. As seen, the use of the BN nozzle of $0.3-\mathrm{mm}$ diameter forms larger melting spots than that of $0.5-\mathrm{mm}$ diameter for both mechanical polished electrode and electrolytic polished electrode. The electrolytic polished electrode makes the electric discharge stable and then the circular melting spot is formed as shown in Fig. 18c, d.

Figure 19 shows melting spots by $\mathrm{N}_{2}$ gas plasma beam. In the similar manner of Ar gas plasma beam, a circular melting spot is formed by using electrolytic polished electrode and it is larger than that by using mechanical polished electrode.

\section{Conclusions}

In order to generate stable electrical discharge of submillimeter size, we examined several variables influencing on constriction of current path: electrode shape, plasma gas, and nozzle diameter of torch. Then, we fabricated experimental two types of torches: TIG- and plasma-type torch. Electrical discharge was experimentally investigated in the range from glow to arc region through glow-arc transition region by using the newly developed power supply.

The results obtained are summarized as follows:

(1) In the experiment with TIG-type torch, three types of discharge modes are confirmed in the current range from 20 to $1,000 \mathrm{~mA}$ through observation of discharge appearance and measurement of voltage waveform: glow mode, glow-arc transition mode, and arc mode.

(2) The pointed electrode electrolytic polish makes cathode spot to be fixed at the electrode tip. The discharge with electrode electrolytic polish is remarkably stable compared with electrode mechanical polish.

(3) In the case of Ar gas discharge with TIG-type torch, the melting spot is not formed at the current of $500 \mathrm{~mA}$ with a discharge time of $10 \mathrm{~ms}$. In the case of plasma-type torch, Ar gas discharge constricted by BN ceramic nozzle forms a melting spot of $100 \mu \mathrm{m}$ at the surface of stainless steel sheet. $\mathrm{N}_{2}$ gas discharge can form a melting spot in both of the TIG- and plasma-type torch.

(4) In order to obtain a stable discharge, the best combination is of the plasma-type torch and pointed electrode electrolytic polish in the scope of experiment. As for plasma gas, $\mathrm{N}_{2}$ gas provides higher power density at the anode than Ar gas.

Open Access This article is distributed under the terms of the Creative Commons Attribution License which permits any use, distribution, and reproduction in any medium, provided the original author(s) and the source are credited.

\section{References}

1. Snoeys R, Staelens F, Dekeyser W (1986) Current trends in nonconventional material removal process. CIRP Ann-Manuf Technol 35(2):467-480

2. Halim A, Mori S, Fujii N, Yasuda K (2005) Plasma welding of thin plate. Q J Jpn Weld Soc 23(2):245-251, in Japanese

3. Nishiguchi K, Tashiro K (1970) Series arcing in plasma arc welding. J Jpn Weld Soc 39(4):269-279, in Japanese

4. Hirata Y, Ozaki K, Ikeda U, Mizoshiri M (2007) Field emission current and vacuum breakdown by a pointed cathode. Thin Solid Films 515(9):4247-4250 
5. Hirata Y, Fukushima M, Sano T, Ozaki K, Ohji T (2000) Micro-arc discharge phenomena. Vacuum 59-1:142-151

6. Hirata Y, Teramoto M, Mizoshiri M, Ikeda U, Ohji T, Ozaki K (2005) Field emission current and electrical breakdown by a pointed cathode coated with carbon-nano-tube. J High Temp Soc 31(3):172-177, in Japanese

7. Maruo H, Hirata Y, Ozaki K (1993) Surface Melting Process with a Thin Electrode in a Micrometer Scale, IIW Doc.212-835-93

8. Maruo H, Hirata Y, Ozaki K (1995) Melting phenomena by microdischarge. Weld Int 9(5):375-383

9. Fowler RH, Nordheim LW (1928) Electron emission in intense electric fields. Proc R Soc 119:173-181

10. Murphy EL, Good RH (1956) Thermionic emission, field emission, and transition region. Phys Rev 102(6):1464-1473

11. Sylvain C, Jean-Luc M (1997) Thermo-field emission: a comparative study. J Phys D Appl Phys 30:776-780
12. Roth JR (1995) Industrial plasma engineering: applications to nonthermal plasma processing. Institute of Physics, London

13. Watanabe S, Saito S, Takahashi K, Onzawa T (2002) V-I characteristic of plasma in the glow-to-Arc transition. Q J Jpn Weld Soc 20(4): 493-498, in Japanese

14. Lu S, Dong W, Li D, Li Y (2009) Numerical study and comparisons of gas tungsten arc properties between $\mathrm{Ar}$ and $\mathrm{N}_{2}$. Comput Mater Sci 45:327-335

15. Boulos MI, Fauchais P, Pfender E (1994) Therm Plasmas-Fundam Appl 1:388-407

16. Lisovskiy VA, Yakovin SD, Yegorenkov VD (2000) Low-pressure gas breakdown in uniform dc electric field. J Phys D Appl Phys 33: 2722-2730

17. Chen J, Farson DF, Rokhlin SI (2009) Experimental study of femtosecond laser-stimulated electrical discharges in small gaps and surface modifications. J Appl Phys 105:013302 